\title{
Comparison of sodium ion levels between an arterial blood gas analyzer and an autoanalyzer in preterm infants admitted to the neonatal intensive care unit: $a$ retrospective study
}

\author{
Hyunho Kim ${ }^{1}$ Jin Kyu Kim ${ }^{1,2^{*}}$ (i) and Soo Chul Cho ${ }^{1,2}$
}

\begin{abstract}
Background: The difference in sodium ion levels determined with direct and indirect methods often exceeds the permissible limit clinically. Additionally, no previous study has assessed the difference in the sodium ion levels between direct and indirect methods in premature infants. Therefore, the present study aimed to compare sodium ion levels obtained using an arterial blood gas analyzer (ABGA; direct method) and an autoanalyzer (indirect method) to determine whether they are equivalent in premature infants.

Methods: The present retrospective study included 450 preterm infants (weight, $<2500 \mathrm{~g}$ ) who were admitted to the neonatal intensive care unit (NICU) of our hospital between March 2012 and April 2014. We compared sodium ion levels in 1041 samples analyzed using an ABGA (Stat Profile ${ }^{\oplus}$ CCX Series, Nova Biomedical, Waltham, MA) and an autoanalyzer (ADVIA ${ }^{\oplus} 2400$ Clinical Chemistry System, Siemens, Tarrytown, NY). The data were evaluated using Spearman's correlation coefficient analysis, Bland-Altman plot, Deming regression analysis, and multivariate logistic regression analysis.

Results: The mean sodium ion levels were $134.6 \pm 3.5 \mathrm{mmol} / \mathrm{L}$ using the ABGA and $138.8 \pm 4.7 \mathrm{mmol} / \mathrm{L}$ using the autoanalyzer $(P<0.001)$. Among the 1041 samples, 957 (91.9\%) showed lower sodium ion levels with the ABGA than with the autoanalyzer and $74(7.1 \%)$ showed lower sodium ion levels with the autoanalyzer than with the ABGA. The incidence of hyponatremia identified using the ABGA was $51.9 \%(541 / 1041)$, while the incidence of hyponatremia identified using the autoanalyzer was only $14.0 \%$ (146/1041). The Deming regression analysis of the sodium ion levels between the ABGA and the autoanalyzer yielded the following formula: autoanalyzer $\mathrm{Na}$ (mmol/ $\mathrm{L})=20.7+(0.9 \times \mathrm{ABGA} \mathrm{Na}[\mathrm{mmol} / \mathrm{L}])$. In the multivariate logistic regression analysis, low plasma protein level $(<4$. $3 \mathrm{~g} / \mathrm{dL}$ ) was found to be an independent risk factor for a sodium ion level difference of $>4 \mathrm{mmol} / \mathrm{L}$ between the two methods (odds ratio $=2.870, P<0.001$ ).

Conclusion: The sodium ion levels determined using the ABGA and the autoanalyzer might not be equivalent in premature infants admitted to the NICU. Therefore, clinicians should be careful when diagnosing sodium ion imbalance in premature infants and providing treatment.
\end{abstract}

Keywords: Blood gas analysis, Hyponatremia, Preterm infant, Protein, Sodium

\footnotetext{
* Correspondence: kyunim99@gmail.com

'Department of Pediatrics, Chonbuk National University Hospital, 20,

Geonji-ro, Deokjin-gu, Jeonju 54907, South Korea

${ }^{2}$ Research Institute of Clinical Medicine of Chonbuk National

University-Biomedical Research Institute of Chonbuk National University

Hospital, Jeonju, South Korea
} 


\section{Background}

Sodium is an essential electrolyte in the intracellular and extracellular fluids of the body. Metabolism is closely associated with sodium, and an imbalance in the sodium ion levels can result in serious life-threatening conditions [1-3]. In the neonatal intensive care unit (NICU), preterm infants are at high risk for an imbalance in the sodium ion levels because of renal immaturity, renal failure, diuretics use, and fluid management. Therefore, it is very important to frequently determine sodium ion levels in preterm infants.

Direct and indirect ion-sensitive electrodes have been used for electrolyte analysis in recent years. The direct electrode analyzes undiluted whole blood. An arterial blood gas analyzer (ABGA) incorporates a direct electrode. An ABGA is useful method to evaluate baby constantly and requires small amounts of blood. The indirect electrode, incorporated in an automated analyzer, analyzes diluted plasma. It is generally used in central hospital laboratories.

The United States Clinical Laboratory Improvement Amendments (US CLIA) 1988 rules allow for a difference of up to $4 \mathrm{mmol} / \mathrm{L}$ in the sodium ion levels [4]. However, the difference in the sodium ion levels between the two types of methods often exceeds the limit clinically. The difference in the sodium ions levels could be caused by a variety of factors, including equipment, transport containers, albumin levels, protein levels, and the patient's medical condition [5-8]. No previous study has assessed the difference in the sodium ion levels between the direct and indirect methods in premature infants. We hypothesized that sodium ion levels obtained using an autoanalyzer (indirect method) and an ABGA (direct method) are equivalent. The present study aimed to compare sodium ion levels between an autoanalyzer and an ABGA to test this hypothesis.

\section{Methods}

The present study included inborn preterm infants (weight, <2500 g) who were admitted to the NICU of Chonbuk National University Hospital between March 2012 and April 2014. We retrospectively analyzed the patient data from the database of the NICU and identified 450 patients who underwent arterial blood collection for electrolyte analysis using both an ABGA and an autoanalyzer on admission and every week after the hospitalization to evaluate sodium level differences at different time points of sample collection.

Arterial blood samples were collected simultaneously for measurements with an ABGA and an autoanalyzer. One sample was collected in a dry heparin syringe (BD Preset $^{\mathrm{TM}}$, BD Diagnostics, Plymouth, UK) and was analyzed using an ABGA (Stat Profile ${ }^{\oplus}$ CCX Series, Nova Biomedical, Waltham, MA). The ABGA undergoes automatic two-point calibration every 2, 4, or $6 \mathrm{~h}$ and single-point calibration every $30 \mathrm{~min}$ or after each sample. Another sample was collected in a microtube (Microtainer ${ }^{\mathrm{TM}}$ tubes \#365978, BD Diagnostics) and was analyzed using a central autoanalyzer $\left(\right.$ ADVIA $^{\oplus} 2400$ Clinical Chemistry System, Siemens, Tarrytown, NY). The autoanalyzer also has an autocalibration system, which checks the accuracy and precision using a sample buffer for sodium. If the measurement is outside the expected range, the autocalibration system posts an alarm message, and the solution is re-analyzed. The samples were immediately sent to our central laboratory and were analyzed. The autoanalyzer simultaneously reports plasma constituents, including plasma protein and albumin. A total of 1041 samples were analyzed using the ABGA and the autoanalyzer.

The data were interpreted based on the indirect sodium level. A serum sodium ion level of $135-145 \mathrm{mmol} / \mathrm{L}$ was considered normal. Patients with a serum sodium ion level $<135 \mathrm{mmol} / \mathrm{L}$ were diagnosed with hyponatremia, and those with a serum sodium ion level $>145 \mathrm{mmol} / \mathrm{L}$ were diagnosed with hypernatremia.

\section{Statistical methods}

Means, standard deviations, and coefficients of variation were calculated. A paired $t$-test was used to compare the sodium ion levels of the ABGA and the autoanalyzer. A Bland-Altman analysis was performed to assess the differences in the sodium ion levels between the ABGA and the autoanalyzer. We defined a sodium ion level of $4 \mathrm{mmol} / \mathrm{L}$ as the acceptable upper limit for the difference between the two methods [4]. Deming regression analysis and a Bland-Altman plot were used to evaluate the sodium ion levels between the ABGA and the autoanalyzer. Logistic regression analysis was performed to identify the risk factors for a high difference in the sodium ion levels between the ABGA and the autoanalyzer. The factors assessed were gestational age, birth body weight, protein levels, and albumin levels. All statistical analyses were performed using SPSS version 18.0 (IBM Corp., Armonk, NY) and MedCalc Statistical Software version 15.8 (MedCalc Software, Mariakerke, Belgium). A $P$-value $<0.05$ was considered to indicate a statistically significant difference.

\section{Results}

The study analyzed data from 450 infants (1041 samples) admitted to the NICU. The gestational age of the infants was $31.4 \pm 3.5$ weeks, and the body weight of the infants was $1605.4 \pm 513.3 \mathrm{~g}$. The average time of sample collection was $10.0 \pm 12.9$ days after the admission to the NICU. Samples were collected on admission and every week. The sodium ion levels did not differ between time points of sample collection. The sodium ion levels were $134.6 \pm 3.5 \mathrm{mmol} / \mathrm{L}$ using the ABGA and $138.8 \pm 4.7 \mathrm{mmol} / \mathrm{L}$ using the autoanalyzer (Table 1 ). 
Table 1 Demographic characteristics and laboratory data of the study infants

\begin{tabular}{lll}
\hline Patient characteristics $(\mathrm{N}=1041)$ & Average & (Range) \\
\hline Gestational age (weeks) & $31.4 \pm 3.5$ & $(23-40)$ \\
Postmenstrual age (weeks) & $33.2 \pm 3.2$ & $(22.6-44.3)$ \\
Time of sample collection (days) & $10.0 \pm 12.9$ & $(1-56)$ \\
Body weight (g) & $1605.4 \pm 513.3$ & $(450-2490)$ \\
Auto-analyzer sodium (mmol/L) & $138.8 \pm 4.7$ & $(119.0-158.0)$ \\
ABGA sodium (mmol/L) & $134.6 \pm 3.5$ & $(117.5-152.2)$ \\
Serum protein $(\mathrm{g} / \mathrm{dL})$ & $4.9 \pm 0.6$ & $(2.2-6.8)$ \\
Serum albumin $(\mathrm{g} / \mathrm{dL})$ & $3.3 \pm 0.4$ & $(1.4-4.4)$ \\
\hline
\end{tabular}

Data are presented as mean \pm SD

$A B G A$ arterial blood gas analyzer

The mean difference was $4.2 \pm 3.6 \mathrm{mmol} / \mathrm{L}(P<0.001)$, correlation coefficient $(\mathrm{R})$ was 0.662 , and adjusted $\mathrm{R}^{2}$ was 0.43 with a $95 \%$ confidence interval of 3.96-4.39. Among the 1041 samples, 957 (91.9\%) showed lower sodium ion levels with the ABGA than with the autoanalyzer and $74(7.1 \%)$ showed lower sodium ion levels with the autoanalyzer than with the ABGA. A BlandAltman comparison of sodium ion levels between the ABGA and the autoanalyzer showed that the limits of agreement were -2.8 to 11.1 (Fig. 1). The Deming regression analysis of the sodium ion levels between the ABGA and the autoanalyzer yielded the following formula: autoanalyzer $\mathrm{Na}(\mathrm{mmol} / \mathrm{L})=20.7+(0.9 \times \mathrm{ABGA}$ $\mathrm{Na}[\mathrm{mmol} / \mathrm{L}])$ (Fig. 2).

Among the patients with normal sodium ion levels and hypernatremia according to the indirect method, the mean differences in the sodium ion levels between the two methods were $4.2 \pm 2.9$ and $9.9 \pm 3.7 \mathrm{mmol} / \mathrm{L}$, respectively $(P<0.001)$, exceeding the acceptable limit defined in the US CLIA 1988 rules. Although the mean difference of $1.0 \mathrm{mmol} / \mathrm{L}$ in patients with hyponatremia was within the acceptable limit defined in the US CLIA 1988 rules, it was statistically significant $(P<0.001)$ (Table 2). The incidence of hyponatremia identified using the ABGA was $51.9 \%$ (541/1041), while the incidence of hyponatremia identified using the autoanalyzer was only $14.0 \%(146 / 1041)$.

In the univariate analysis, a significant association was found between a sodium ion difference of $>4 \mathrm{mmol} / \mathrm{L}$ and the plasma protein level. In the multiple logistic regression analysis, the plasma protein level was identified as an independent risk factor for a sodium ion level difference of $>4 \mathrm{mmol} / \mathrm{L}$ between the methods (odds ratio $=2.870, P<0.001)($ Table 3$)$.

\section{Discussion}

In the present study, we found that the sodium ion levels in preterm infants simultaneously determined using an ABGA and an autoanalyzer were significantly different.

In correlation analysis, a close relationship was identified in the sodium ion levels between the ABGA and the autoanalyzer $\left(r^{2}=0.44\right)$. However, the mean difference ( $4.2 \mathrm{mmol} / \mathrm{L}$ ) exceeded the limit imposed by the US CLIA 1988 rules (4 mmol/L) [4]. Additionally, the mean difference was highest in patients with hypernatremia $(9.9 \mathrm{mmol} / \mathrm{L})$. In multiple logistic regression analysis, the

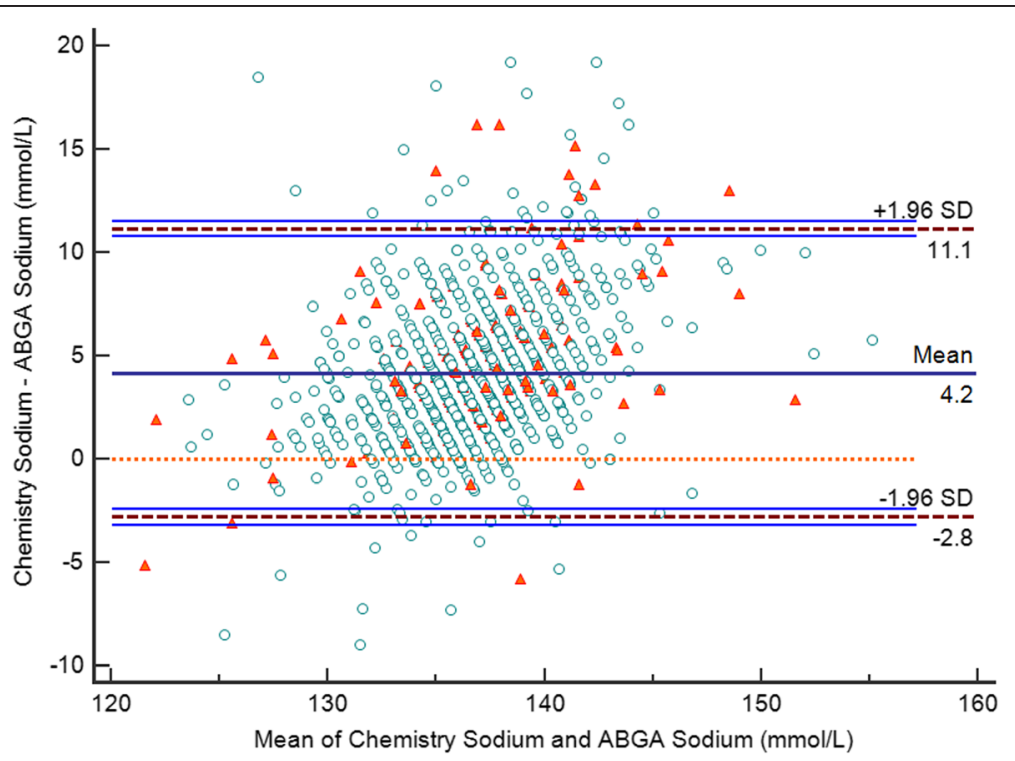

Fig. 1 Bland-Altman plot of sodium ion levels determined using the arterial blood gas analyzer and autoanalyzer. The horizontal axis shows the mean of the sodium ion level determined using the blood chemistry test and the sodium ion level measured with the ABGA, while the differences in the sodium ion levels between the arterial blood gas analyzer and the autoanalyzer are presented on the $Y$-axis. Circles indicate low serum protein level $(<4.3 \mathrm{~g} / \mathrm{dL})$, while triangles indicate high serum protein level $(\geq 4.3 \mathrm{~g} / \mathrm{dL})$ 


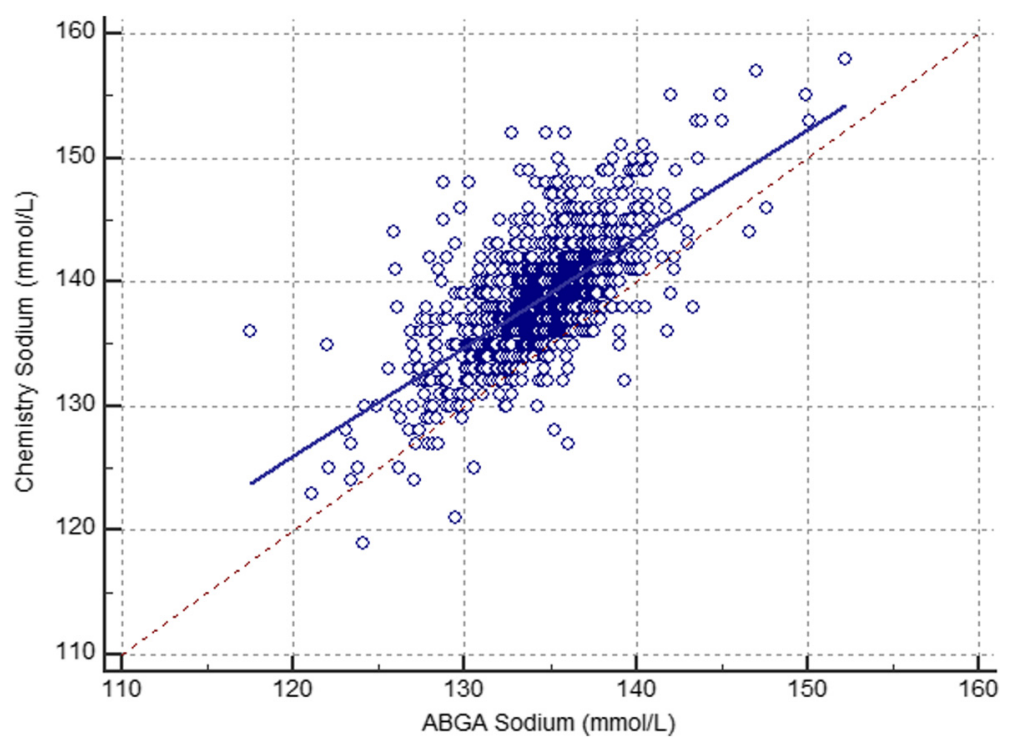

Fig. 2 Deming fit (solid blue line) for sodium ion levels. The sodium ion levels determined using the arterial blood gas analyzer (ABGA) are presented on the X-axis, while the sodium ion levels determined using the chemistry are presented on the $Y$-axis. Deming regression equation: chemistry $\mathrm{Na}(\mathrm{mmol} / \mathrm{L})=20.7+(0.9 \times \mathrm{ABGA} \mathrm{Na}[\mathrm{mmol} / \mathrm{L}]), R^{2}=0.43$

plasma protein level was identified as an independent risk factor for a sodium ion level difference of $>4 \mathrm{mmol} /$ $\mathrm{L}$ between the methods.

The difference in the sodium ion levels between the ABGA and the autoanalyzer might be explained by various factors. Collection and transportation of the samples might have contributed to the difference in the sodium ion levels. However, the heparin syringe used in this study for sample collection for the ABGA includes lyophilized lithium heparin (spray-dried calcium-balanced lithium heparin), and this syringe has been shown to rarely cause bias $[5,9]$. The blood collection tube used in this study for sample collection for the autoanalyzer is a microtube containing the clot activator $\mathrm{SST}^{\mathrm{TM}} \mathrm{Gel}$. Because the microtube is filled with only $400-600 \mu \mathrm{L}$ of blood, bias is minimal.

Previous studies have shown that solid elements of blood, including proteins and lipids, can cause a false diagnosis of hyponatremia (pseudohyponatremia) via an

Table 2 Classified analysis of the differences in the sodium ion levels between the arterial blood gas analyzer (ABGA) and the autoanalyzer

\begin{tabular}{llll}
\hline $\begin{array}{l}\text { Indirect Method } \\
(\mathrm{mmol} / \mathrm{L})\end{array}$ & \multicolumn{3}{l}{ Sodium concentration } \\
\cline { 2 - 4 } & Cases $(N=1041)$ & Mean & $P$-value \\
\hline$<135$ & 146 & $1.0 \pm 2.7$ & $<0.001$ \\
$135-145$ & 815 & $4.2 \pm 2.9$ & $<0.001$ \\
$>145$ & 80 & $9.9 \pm 3.7$ & $<0.001$ \\
Total & 1041 & $4.2 \pm 3.6$ & $<0.001$
\end{tabular}

Data are presented as mean \pm SD electrolyte exclusion effect when an indirect method is used $[4,10,11]$. It is known that younger and smaller infants tend to have low protein levels initially. In the present study, the sodium ion levels determined using the indirect method were higher than those determined using the direct method. Moreover, the difference in the sodium ion levels exceeded $4 \mathrm{mmol} / \mathrm{L}$ more often in infants with low plasma protein level $(<4.3 \mathrm{~g} / \mathrm{dL})$ than in those with high plasma protein level $(\geq 4.3$ g.dL). Previous studies in adults showed that the difference in the sodium ion levels between the two methods can be large in patients with hypoalbuminemia and low serum total protein $[6,12]$.

The sodium ion levels determined using the ABGA and the autoanalyzer were not equivalent in premature infants admitted to the NICU. Therefore, clinicians should be careful when diagnosing sodium ion imbalance and devising treatment. In particular, the difference between the two methods can lead to inaccurate anion gap measurement, resulting in incorrect determination of metabolic status [13]. For correcting inconsistencies for adults with abnormal protein levels, especially for those with multiple myeloma, some hospitals use a compensation equation [14]. However, there was no previous study on the difference in the sodium ion levels between the direct and indirect methods in premature infants, and the critical difference in the neonatal period has not been determined. Our study clarifies the difference in the sodium ion levels between the direct and indirect methods in premature infants. The use of a compensation equation in each hospital is a possible solution to 
Table 3 Unadjusted and adjusted odds ratios for the risk of exceeding the upper limit of the sodium ion level (4 mmol/L) according to the protein and albumin levels [15-17]

\begin{tabular}{|c|c|c|c|c|c|c|c|}
\hline \multirow[t]{2}{*}{ Variable } & \multirow[t]{2}{*}{ Cases $(N=1041)$} & \multicolumn{3}{|c|}{ Unadjusted } & \multicolumn{3}{|c|}{ Adjusted } \\
\hline & & $\overline{\mathrm{OR}}$ & $95 \% \mathrm{Cl}$ & $P$ value & $\overline{\mathrm{OR}}$ & $95 \% \mathrm{Cl}$ & $P$ value \\
\hline \multicolumn{8}{|c|}{ Gestational age (wk) } \\
\hline$<34$ & 700 & 0.914 & $0.705-1.185$ & 0.498 & 0.821 & $0.607-1.112$ & 0.203 \\
\hline$\geq 34$ & 341 & 1.000 & (Reference) & & 1.000 & (Reference) & \\
\hline \multicolumn{8}{|c|}{ Birth weight (g) } \\
\hline$<1500$ & 442 & 1.071 & $0.837-1.370$ & 0.585 & 1.112 & $0.823-1.503$ & 0.490 \\
\hline$\geq 1500$ & 599 & 1.000 & (Reference) & & 1.000 & (Reference) & \\
\hline \multicolumn{8}{|c|}{ Protein (g/dL) } \\
\hline$<4.3$ & 147 & 2.565 & $1.779-3.698$ & $<0.001$ & 2.870 & $1.920-4.290$ & $<0.001$ \\
\hline$\geq 4.3$ & 894 & 1.000 & (Reference) & & 1.000 & (Reference) & \\
\hline \multicolumn{8}{|c|}{ Albumin (g/dL) } \\
\hline$<2.2$ & 1024 & 0.981 & $0.435-2.210$ & 0.963 & 0.472 & $0.197-1.130$ & 0.920 \\
\hline$\geq 2.2$ & 17 & 1.000 & (Reference) & & 1.000 & (Reference) & \\
\hline \multicolumn{8}{|c|}{ Sampling day (d) } \\
\hline$\leq 7$ & 708 & 1.360 & $1.045-1.769$ & 0.022 & 1.326 & $0.990-1.775$ & 0.058 \\
\hline$>7$ & 333 & 1.000 & (Reference) & & 1.000 & (Reference) & \\
\hline
\end{tabular}

OR odds ratio, $95 \% \mathrm{Cl} 95 \%$ confidence interval

overcome the inconsistency in sodium ion levels assessed using the direct and indirect methods. Additionally, the direct method might be preferable $[4,6]$. The direct method is not influenced by the solid components of blood, which could lead to a false result, and does not require dilution of the sample; therefore, the direct method is considered to be more accurate and consistent for the evaluation of sodium ion levels than the indirect method [12].

The main limitation of the present study is its retrospective design. However, the samples analyzed using the ABGA and the autoanalyzer were obtained at the same time points. Another limitation is that the levels of lipid, one of the solid components of blood, were not measured routinely, precluding the analysis of the effect of lipid on the difference in sodium levels determined with the two methods. Despite these limitations, the results can be used for more precise determination of sodium levels in preterm infants, and are therefore important.

\section{Conclusion}

The sodium ion levels determined using the ABGA and the autoanalyzer might not be equivalent in premature infants admitted to the NICU. Although the direct method has been shown to be suitable for assessing sodium ion levels in previous studies, these studies were performed in adults; therefore, clinicians should be careful when diagnosing sodium ion imbalance in premature infants and providing treatment. Further studies are needed to determine the factors responsible for the inconsistency in the sodium ion levels between the direct and indirect methods.

\section{Additional file}

Additional file 1: The datasets supporting the conclusion of this study. (XLSX $820 \mathrm{~kb})$

\section{Abbreviations}

ABGA: arterial blood gas analyzer; NICU: neonatal intensive care unit; US CLIA: The United States clinical laboratory improvement amendments

\section{Acknowledgements}

We gratefully acknowledge Prof. Won Soon Park and Prof. Yun Sil Chang for providing input on the study design, and Dr. Min Lee for helping with the acquisition of data.

\section{Funding}

None.

Availability of data and materials

The datasets supporting the conclusions of this article is included within the manuscript and Additional file 1.

Authors' contributions

Study conception and design: JKK. Acquisition of data: HK and JKK. Analysis and interpretation of data: JKK and SCC. Preparation, critical revision: HK and JKK. All authors have read and approved the final version of the manuscript.

\section{Competing interests}

The authors declare that they have competing interest.

Consent for publication

Not applicable. 


\section{Ethics approval and consent to participate}

Data collection was approved by the Institutional Review Board of Chonbuk National University Hospital. The informed consent requirements for this retrospective chart review were waived by the Institutional Review Board. As the study used de-identified routinely collected data, the consent for parents was waived.

Received: 18 November 2015 Accepted: 12 July 2016

\section{Published online: 20 July 2016}

\section{References}

1. Kloiber LL, Winn NJ, Shaffer SG, Hassanein RS. Late hyponatremia in verylow-birth-weight infants: incidence and associated risk factors. J Am Diet Assoc. 1996;96:880-4.

2. Moritz ML, Ayus JC. Hyponatremia in preterm neonates: Not a benign condition. Pediatrics. 2009;124:e1014-6.

3. MODI N. Hyponatraemia in the newborn. Arch Dis Child Fetal Neonatal Ed. 1998;78:F81-4

4. Carl A, Edward R, David E. Tietz Textbook of Clinical Chemistry and Molecular Diagnostics. 4th ed. St. Louis, Mo: Elsevier Inc.; 2006.

5. Lima-Oliveira G, Lippi G, Salvagno GL, Montagnana M, Picheth G, Guidi GC. Different manufacturers of syringes: a new source of variability in blood gas, acid-base balance and related laboratory test? Clin Biochem. 2012;45:683-7.

6. Story DA, Morimatsu H, Egi M, Bellomo R. The effect of albumin concentration on plasma sodium and chloride measurements in critically ill patients. Anesth Analg. 2007;104:893-7.

7. Dimeski G, Barnett RJ. Effects of total plasma protein concentration on plasma sodium, potassium and chloride measurements by an indirect ion selective electrode measuring system. Crit Care Resusc J Australas Acad Crit Care Med. 2005;7:12-5.

8. Sharma B, Sarmah D. A comparative evaluation of sodium and potassium measurements by flame photometer and by direct ISE methods. Int J Health Sci Res IJHSR. 2013:3:59-65.

9. Yip PM, Chan MK, Zielinski N, Adeli K. Heparin interference in whole blood sodium measurements in a pediatric setting. Clin Biochem. 2006:39:391-5.

10. Weisberg LS. Pseudohyponatremia: a reappraisal. Am J Med. 1989;86:315-8.

11. Kim G-H. Pseudohyponatremia: does It matter in current clinical practice? Electrolytes Blood Press E BP. 2006;4:77-82.

12. Chow E, Fox N, Gama R. Effect of low serum total protein on sodium and potassium measurement by ion-selective electrodes in critically ill patients. Br J Biomed Sci. 2008;65:128-31.

13. Morimatsu H, Rocktäschel J, Bellomo R, Uchino S, Goldsmith D, Gutteridge G. Comparison of point-of-care versus central laboratory measurement of electrolyte concentrations on calculations of the anion gap and the strong ion difference. Anesthesiology. 2003;98:1077-84.

14. Lang T, Prinsloo P, Broughton AF, Lawson N, Marenah CB. Effect of low protein concentration on serum sodium measurement: pseudohypernatraemia and pseudonormonatraemia! Ann Clin Biochem. 2002;39:66-7.

15. The Department of Health and Human Service: the state of Victoria. https:// www2.health.vic.gov.au/hospitals-and-health-services/patient-care/perinatalreproductive/neonatalehandbook/pathology/normal-laboratory-values. Accessed 16 July, 2014.

16. Robert MK, Bonita FS, Joseph WS, Nina FS, Richard EB : Nelson Textbook of Pediatrics. 20th ed, Elsevier; 2015.

17. Karl B, Günther B, Alexander Roithmaier MD, Martin G, Alfred P, Versmold MDHT. Body composition, nutrition and fluid balance during the first two weeks of life in preterm neonates weighing less than 1500 grams. J Pediatr. 1991:118:615-20.

\section{Submit your next manuscript to BioMed Central and we will help you at every step:}

- We accept pre-submission inquiries

- Our selector tool helps you to find the most relevant journal

- We provide round the clock customer support

- Convenient online submission

- Thorough peer review

- Inclusion in PubMed and all major indexing services

- Maximum visibility for your research

Submit your manuscript at www.biomedcentral.com/submit 